\title{
O Uso de Objetos de Aprendizagem com Alunos Surdos no Ensino Superior
}

\author{
Deisi Becker', Jocimara Mauer², Simone Emer³, Patrícia A. Behar ${ }^{4}$, Sandra Maria \\ Assumpção ${ }^{5}$
}

${ }^{1}$ Doutoranda, Pós-Graduação em Administração, Escola de Administração Universidade Federal do Rio Grande do Sul (UFRGS)

2 Pós Graduada Gestão Estratégica de Vendas e Marketing de relacionamento Faculdade da Serra Gaúcha (FSG)

${ }^{3}$ Mestra, em Educação - Universidade Federal do Rio Grande do Sul (UFRGS)

${ }^{4}$ Doutora em Ciência da Computação, Pós-Graduação em Informática na Educação, Universidade Federal do Rio Grande do Sul (UFRGS)

${ }^{5}$ Mestra, em Educação - Universidade Federal do Rio Grande do Sul (UFRGS) deisibeckerabol.com.br, jocimara mauer@hotmail.com,

Simone.emerafsg.br, patricia.behar@ufrgs.br, sandradeia@gmail.com

Resumo. Este trabalho buscou investigar a acessibilidade de objetos de aprendizagem para acadêmicos surdos no ensino superior a partir de sistemas de recomendação. $O$ domínio trabalhado foi $o$ tecnológico e suas competências para que o uso das tecnologias digitais pudesse ser expandido, atingindo assim, este público específico. Os sistemas de recomendação possuem essa função e o desafio foi encontrar objetos de aprendizagem destinados aos alunos surdos. Na pesquisa, 12 professores que atuaram no ensino superior, participaram da oficina com 05 alunos deficientes auditivos. Os resultados, a partir da abordagem qualitativa, exploratória, realizada com a técnica de observação, demonstram que houve dificuldade em encontrar tais objetos.

\begin{abstract}
This study sought to investigate the accessibility of learning objects for deaf students in higher education from recommendation systems. The worked domain was the technological and their competencies so that the use of digital technologies could be expanded, thus reaching this specific audience. The recommendation systems have this function and the challenge was to find learning objects intended for deaf students. In the survey, twelve teachers who worked in higher education participated in the workshop with five deaf students. The results from the qualitative, exploratory approach, performed with the technique of observation, show that there was difficulty in finding such objects.
\end{abstract}

\section{Introdução}

Para que a temática desenvolvida nesta pesquisa seja direcionada, o objetivo consiste em investigar a acessibilidade de objetos de aprendizagem para acadêmicos surdos no ensino superior a partir de sistemas de recomendação. Esta investigação se deu por meio da aplicação de uma oficina de tecnologia educacional, a qual foi uma atividade da disciplina de Tecnologias Educacionais do Curso de Especialização de Docência no Ensino Superior. Os professores deste curso aplicaram os objetos de aprendizagem com cinco alunos surdos para análise da acessibilidade. 
Para esta organização foi necessário propor alguns objetivos específicos aos professores que aplicariam a oficina, tais como: estudar temas importantes para o planejamento da atividade na oficina, como: Domínio, Competências, Objetos de Aprendizagem, Recomendação e Inclusão. Elaborar um plano pedagógico. Pesquisar e selecionar um objeto de aprendizagem. Analisar os critérios de acessibilidade do objeto de aprendizagem. Aplicar o objeto de aprendizagem aos alunos com olhar criterioso referente às facilidades e dificuldades encontradas.

\section{Domínios, Competências em EaD e Objetos de Aprendizagem}

Para que o aluno consiga desenvolver bem suas atividades com o uso de tecnologias digitais, são necessárias competências para trabalhar com hardware e software (MACHADO, LONGHI E BEHAR, 2013). O domínio tecnológico é compreendido como "[...] um conjunto de competências relacionadas ao uso dos recursos tecnológicos empregadas tanto na modalidade presencial, semipresencial ou totalmente a distância" (MACHADO, LONGHI E BEHAR, 2013, p. 57).

Todas as competências listadas e outras que poderão ser elencadas são formadas pelo CHA (conhecimentos, habilidades e atitudes). Na educação, a discussão centrada em competências está alicerçada em uma forma diferente da tradicional, que se baseia em trabalhar currículo (BEHAR et al, 2013). No caso do presente estudo, a necessidade desta convergência é ainda mais especial e focada por se tratar de pessoas com deficiência auditiva.

\section{Recomendação de conteúdos e Inclusão}

Um dos grandes desafios atuais, falando especificamente do mundo virtual, refere-se à busca e seleção de materiais disponíveis na internet (CAZELLA, NUNES e REATEGUI, 2013). Os sistemas de recomendação (SR) de produtos, serviços, informações, pessoas, permite aos usuários maior assertividade na busca e menos investimento de tempo nesta relação. Segundo Cazella, Nunes e Reategui (2013) os SR e personalização "cativam" o usuário por apresentar-se como um instrumento facilitador.

Para isso, o sistema de recomendação poderá facilitar o processo de aprendizagem, tanto de professores como dos alunos, encurtando e filtrando as informações pesquisadas. Os sistemas de recomendação possibilitarão o acesso mais rápido e confiante da informação, ao mesmo tempo, que sendo baseado em competência, direciona o processo de desenvolvimento do conhecimento, habilidade e atitudes necessárias para a realidade problematizada ou ao objeto de aprendizagem proposto como ferramenta educacional, em especial na experiência relatada de inclusão.

Abordar a importância das práticas educativas nos projetos pedagógicos inclusivos é fundamental, Conforto e Santarosa (2010) discorrem sobre a importância de respeitar a diversidade humana. Pensando em uma forma de inclusão significativa para alunos deficientes auditivos.

A inclusão sócio-digital refere-se a ações de inserção no cunho tecnológico e político que promovam o desenvolvimento de tecnologias que ampliem a acessibilidade de pessoas com deficiências. Desse modo, pode-se observar a importância do uso de objetos de aprendizagem para aplicação em alunos deficientes auditivos, assim contribuindo com a educação significativa desses. Uma vez que, práticas pedagógicas 
utilizadas atualmente em alguns momentos não são completamente satisfatórias nos resultados da aprendizagem de alunos surdos, pensar em uma alternativa que diminua a lacuna no processo de ensino aprendizagem é fundamental. Neste sentido, é importante realizar uma ação-reflexão-ação, em relação ao uso de objetos de aprendizagem em sala de aula.

\section{Procedimentos metodológicos}

A investigação foi organizada por meio de uma pesquisa exploratória, a qual não requer a elaboração de hipóteses a serem testadas no trabalho (GIL, 2004). O objetivo desta pesquisa foi investigar a acessibilidade de objetos de aprendizagem para acadêmicos surdos no ensino superior a partir de sistemas de recomendação, o que justifica a escolha do tipo de pesquisa para explorar o contexto proposto. O procedimento selecionado para pesquisa foi tratar os dados por meio de uma abordagem qualitativa, devido ao instrumento de pesquisa proposto com perguntas abertas e fechadas (GIL, 2004). Foi aplicada a técnica de observação com roteiro orientado. A observação é uma técnica de coleta de coleta de dados para conseguir informações e os sentidos na obtenção de determinados aspectos da realidade. (BEUREN, 2009, p. 131).

E para análise dos dados foi escolhida a técnica de análise de conteúdo. O princípio da análise de conteúdo é definido na demonstração da estrutura e dos elementos desse conteúdo para esclarecer diferentes características e extrair sua significação (BARDIN, 2002).

A pesquisa ocorreu na disciplina de Tecnologias Educacionais para o Curso de Especialização em Docência no Ensino Superior da Faculdade da Serra Gaúcha no município de Caxias do Sul. A turma é composta por 12 professores que pretendem futuramente atuar no ensino superior. Vale ressaltar que a instituição possui uma forte política de inclusão, sendo que, nesta realidade possui atualmente nove acadêmicos surdos. Destes, cinco acadêmicos fizeram parte da aplicação da pesquisa com os objetos de aprendizagem. A pesquisa realizada pelos professores ficou organizada da seguinte forma:

a) Estudo teórico por parte dos professores que aplicaram os objetos de aprendizagem com os alunos surdos na oficina. Estudaram os temas: Domínio, Competências, Objetos de Aprendizagem, Recomendação e Inclusão. Elaboração do plano pedagógico: nesse processo os professores identificaram o domínio, a competência, o desenvolvimento do conhecimento, habilidade e atitude (CHA), pesquisaram e escolheram um objeto de aprendizagem para aplicação e análise da acessibilidade. Pesquisa no sistema de recomendação no Google alerts de objetos de aprendizagem acessível. Descrição da atividade que seria desenvolvida na oficina. Testagem do uso dos objetos de aprendizagem para serem aplicados na oficina. Conhecer os alunos surdos. Explicar a proposta da atividade de análise de acessibilidade dos objetos de aprendizagem. Aplicação do objeto de aprendizagem com os alunos surdos. Discussão de apresentação dos resultados da aplicação. Preenchimento de um instrumento de coleta de dados para levantar a percepção dos professores na prática realizada.

A turma da disciplina de Tecnologias Educacionais recebeu aulas de preparação, por meio de leituras e discussões, referente aos temas de domínios, competências, objetos de aprendizagem, recomendação e inclusão. Depois de cinco aulas de estudo, os 
alunos organizaram uma oficina de prática no laboratório de informática para aplicação do objeto de aprendizagem com alunos surdos.

\section{Apresentação e análise dos resultados}

O experimento de pesquisa realizado com a disciplina de Tecnologias Educacionais do Curso de Especialização em Docência no Ensino Superior pontuou algumas questões teóricas específicas. Inicialmente foi solicitado aos professores que aplicariam a oficina, para organizarem o seu planejamento pedagógico.

Durante a aplicação da Oficina foi possível perceber as dificuldades enfrentadas pelos professores, inicialmente referente à comunicação e depois aos objetos de aprendizagem que exigiam pesquisa do aluno em textos escritos. Novamente enfrentavam a mesma dificuldade na comunicação, no entanto, agora na comunicação escrita. Pois para os surdos o português apresenta-se como uma segunda língua. Sendo que, os professores que aplicaram a oficina de tecnologia não encontraram objetos de aprendizagem especificamente para surdos no ensino superior, apenas para ensino básico. Neste contexto, eles procuraram se adequar a situação e buscar objetos de aprendizagem que pudessem ser utilizados no ensino superior, mesmo sem as características de acessibilidade e tendo que efetuar a busca manualmente.

Logo depois da oficina de Tecnologias Aplicadas à Educação, os professores receberam um instrumento de coleta de dados, organizados com a estrutura de escala Likert, para apresentarem a sua percepção da prática vivenciada. Os professores quando questionados com relação ao planejamento pedagógico, ao desenvolvimento da competência e ao uso do objeto de aprendizagem, se os objetivos estabelecidos, foram atingidos ou não, apenas um concordou parcialmente, os outros nove professores afirmam ter atingido os objetivos de forma inclusiva. Quando os professores foram interrogados quanto à facilidade do aluno surdo para realizar a atividade no objeto de aprendizagem, a maioria afirma que isso ocorreu de modo muito satisfatório, apenas um professor relatou que o aluno apresentou dificuldades. A dificuldade relatada foi $o$ tempo que este aluno demorou em realizar a atividade, devido a leitura envolvida.

Mesmo enfrentando algumas dificuldades na aplicação, conforme presenciada na técnica de observação, a maioria afirma não ter dificuldade de acessibilidade para uso do objeto de aprendizagem frente à surdez. No entanto, três professores afirmam verificar dificuldades de acessibilidade no objeto com relação à atividade desenvolvida. Assim como, encontraram muitas dificuldades para verificar a existência de objetos de aprendizagem que pudessem ser aplicados e que facilitassem a acessibilidade aos acadêmicos surdos. Pode-se perceber que os sistemas de recomendação facilitariam a prática pedagógica docente se recomendassem os objetos com apontamentos de acessibilidade para pessoas com deficiência e mesmo para os alunos seria melhor, pois uma das questões segundo Cazella, Nunes e Reategui (2013), que"cativam" o usuário é a personalização, por apresentar-se como um instrumento facilitador.

Quando afirmado ao professor que a competência de letramento digital organizada nos conhecimentos, habilidades e atitudes foram respondidas na atividade proposta com o uso do objeto de aprendizagem, a maioria concorda plenamente com a efetivação deste processo. Sendo que, apenas dois professores não concordaram plenamente. Foi solicitado aos professores que relatassem as suas facilidades e dificuldades na prática da Oficina. 
Os professores constantemente relataram a dificuldade para encontrar objetos de aprendizagem que respondam as necessidades de alunos surdos e sua acessibilidade. Ao mesmo tempo em que destacaram a importância desta experiência para conhecer esta realidade, a qual se organizou em quatro dimensões, são elas: desenvolvimento da competência, o uso do objeto de aprendizagem, a inclusão e acessibilidade, assim como, a falta de sistemas de recomendação que respondam a este contexto. Em resumo com o processo de pesquisa e o resultado é possível considerar algumas questões relevantes que ocorreram na pesquisa, como o planejamento pedagógico ter sido executado para buscar o desenvolvimento das competências por meio do uso dos objetos de aprendizagem numa perspectiva inclusiva para alunos surdos no ensino superior, o que muitos professores afirmaram ser um desafio no uso da tecnologia e a inclusão.

\section{Considerações finais}

O objetivo desta pesquisa foi realizado em parte, pois nesse breve tempo de investigação, não foi encontrado um sistema de recomendação que apresente objetos de aprendizagem acessíveis para alunos surdos no ensino superior. Os objetos de aprendizagem selecionados para aplicação foram pesquisados e adaptados manualmente para se tornarem acessíveis aos alunos surdos, por meio de legendas e com apoio da intérprete. $\mathrm{O}$ que se pode perceber com esta pesquisa é que existem duas problemáticas abertas para investigação. Primeiro, os objetos de aprendizagem acessíveis para surdos no ensino superior, nesta pesquisa encontramos apenas objetos acessíveis para surdez na educação básica. Segundo, não encontramos sistemas de recomendação que apresentem objetos de aprendizagem acessíveis. Estas duas problemáticas expostas para futuras pesquisas na área de educação, tecnologia e inclusão, também apresentam-se como limitações da investigação. Então, foi realizada a aplicação dos objetos de aprendizagem procurando adaptar os mesmos ao contexto da proposta inicial.

\section{Referências}

Bardin, Laurence. Análise de conteúdo. Trad. Luís Antero Reto e Augusto Pinheiro. Lisboa: Edições 70, 2002.

Behar, P. A.; Gaspar, M. I. Uma perspectiva curricular com base em objetos de aprendizagem. 2007. Disponível em: <http://reposital.cuaed.unam.mx:8080/jspui

/bitstream/123456789/1070/1/37-PB.PDF >. Acesso em: 20 de jun. 2014.

Beuren, Ilse Maria (Org.). Como elaborar trabalhos monográficos: teoria e prática. São Paulo: Atlas, 2009.

Caiado, Katia; Jesus, Denise: Baptista, Claudio. (Org.s) Professores e educação especial: formação em foco (vol. 1 e 2). Porto Alegre: Mediação, 2011.

Cazella, S. C.; Nunes, M. A. S. N.; e Reategui, E. B. A ciência da Opinião: Estado da arte em Sistemas de Recomendação. 2013. Disponível em: <http://www.do.ufgd.edu.br/ WillianAmorim/TAIC022013_arquivos/Artigo2.pdf>. Acesso em: 23 abril 2014.

Conforto D.; Santarosa, L. Formação de professores: Construindo cenários inclusivos. In. CINTED-UFRGS, 2010. Disponível em: <http://seer.ufrgs.br/index.php/renote/article /view/15191/8956>. Acesso em: 15 de jun. 2014.

Gil, Antônio Carlos. Como elaborar projetos de pesquisa. São Paulo: Atlas, 2004.

Machado, L. R.; Longhi, M. T.; Behar, P. A. Domínio tecnológico: saberes e fazeres na educação a distância. In: BEHAR, Patricia, A. Competências em educação a distância. Porto Alegre: Penso, 2013. 